\title{
Anatomical Variation of the Auriculotemporal Nerve in Thai Cadavers
}

\author{
Variación Anatómica del Nervio Auriculotemporal en Cadáveres Tailandeses
}

Rachanee Chanasong; Keerati Kiti-ngoen; Chalit Khaodaeng; Natthiya Sakulsak \& Narawadee Choompoo

CHANASONG, R.; KITI-NGOEN, K.; KHAODAENG, C.; SAKULSAK, N. \& CHOOMPOO, N. Anatomical variation of the auriculotemporal nerve in Thai cadavers. Int. J. Morphol., 38(6):1657-1661, 2020.

SUMMARY: The auriculotemporal nerve (ATN) is an important structure lying within a limited area of an infratemporal region (ITR). The ATN is originated from the posterior branch of the mandibular division of the trigeminal nerve (V3). The ATN conveys somatosensory, secretomotor, and parasympathetic fibres of the V3 and gustatory nerve (CN IX). In literature, the most common pattern of the ATN is composed of 2 roots that encloses the middle meningeal artery (MMA). However, in many studies, it has been reported that there are many variations in ATN pattern formation. To study the variation of ATN pattern formation in Thai cadavers, 73 hemifaces from 39 Thai embalmed cadavers were dissected and the relations of the ATN to the MMA were recorded. This study concluded that there were 4 patterns observed in Thai cadavers. The common pattern is 2 roots $(67.1 \%), 3$ roots $(15.1 \%), 1$ root $(9.6 \%)$, and 4 roots $(8.2 \%)$. Knowledge of this variation in the ATN may be useful in understanding the symptoms of temporo-orofacial pain, paresthesia of temporomandibular joint (TMJ), possible side effects from the TMJ surgery and the efficiency of auriculotemporal nerve block for regional anesthesia of the temporomandibular joint in Thai people.

KEY WORDS: Auriculotemporal nerve; Inferior alveolar nerve; Middle meningeal artery; Variation; Thai cadaver.

\section{INTRODUCTION}

The posterior division of mandibular nerve (PMN) passes through the foramen ovale on the base of the skull and branches into ATN, inferior alveolar nerve (IAN), and lingual nerve (LN). The ATN is an important structure which is closely related to pterygoid muscle, branches of the maxillary artery, and mandibular nerve within the infratemporal fossa (Gülekon et al., 2005). The common representation of the ATN in anatomical literature is primarily two roots and encircle the MMA in the infratemporal fossa (Drake et al., 2005; Komarnitki et al., 2015). The nerve runs deep into the lateral pterygoid muscle in between of sphenomandibular ligament and the neck of mandible before dividing into the auricular and temporal parts. The ATN crosses medial to TMJ and goes upward posteriorly close to superficial temporal vessels (Dias et al., 2015). However, the ATN within the infratemporal fossa has been found to give a diversity of patterns in many populations (Gülekon et al.; Dias et al.; Komarnitki et al., 2015). The neurovascular topography variations of the ATN are the relation to MMA (Baumel et al., 1971; Dias et al.) and the TMJ (Schmidt et al., 1998), the connection with IAN (Baumel et al.; Gülekon et al.), and the number of roots composing to the ATN
(Komarnitki et al., 2012). The alteration in ATN pattern has been reported 1-5 roots and the most common phenotype approximately $31-72 \%$ is the 2 roots model (Kari \& Tresco, 2019). The variation in communicating branches from IAN and LN reported in previous studies (Bhardwaj et al., 2014; Bhadoria et al., 2016) and demonstrated in 10-30 \% between the ATN and the IAN (Gülekon et al.; Komarnitki et al., 2012).

The main branch of ATN as a so-called "superficial temporal ramus" transmits the sensation of the TMJ, parotid gland, external acoustic meatus, tympanic membrane, and auricle (Kari \& Tresco, 2019). The ATN has no motor function, however, the autonomic innervation conveys via the ATN are terminated to the parotid gland, scalp, and face. The closed anatomical relation of the ATN with other structures or the damage of this nerve during surgical procedures may involve in clinical symptoms of migraine and headache, pain and paresthesis in the temporo-facial regions, external auditory canal, and TMJ (Gülekon et al.; Komarnitki et al., 2012). The alteration of the ATN location and distribution is feasible to generate the ATN compression 
with other surrounding components. The ATN entrapments by superficial temporal artery, the masticatory system either upon mastication or pathology such as lateral pterygoid hypertrophy may cause temple headache, and paresthesia of the TMJ, external acoustic canal, and facial muscle relating to the region of nerve innervation (Komarnitki et al., 2012; Soni et al., 2019). The adverse side effect from parotidectomy, TMJ reconstruction, and maxillofacial surgery may disturb ATN regeneration leading to a disorder of the ATN (Soni et al.).

The anatomical topography of the ITR in the Thai population is limited. Singsorn et al. (2015) reported 5 types of communication among PMN observing from 55 hemisectioned heads of the embalmed Thai cadavers age between 45-87 years. The most common connection was between LN and IAN (10 \%), and between IAN and ATN (7.14 \%). The entrapment of PMN by the lateral pterygoid muscle was found $9 \%$ in 100 hemi-faces studying in the Thai cadavers aged between 56-74 years (Boonruangsri et al., 2019). The relation of the neurovascular system and masticatory muscles of the infratemporal region is important not only for surgical practices but also for the symptomatology of facial pain, headache, and paresthesia (Gülekon et al.; Soni et $a l$.). It is essential to be cautious of the ATN variation and its distribution in terms of clinical diagnosis and procedure. The purpose of this research is to reveal the stereotypic pattern forming the ATN and clarify the relationship to other structures in the Thai citizen due to the limited information in this area.

\section{MATERIAL AND METHOD}

The study was conducted in 73 hemifaces from 39 Thai embalmed cadavers, dissected in the infratemporal region, and observed for the branching emerging from the trunk of the posterior division of mandibular nerve to form the ATN, as well as the relationship of the ATN to the middle meningeal artery and other branches of the PMN. The study was conducted during a routine dissection course for health science students at the Department of Anatomy, Faculty of Medical Science, Naresuan University, Phitsanulok, Thailand. Formalin-fixed Thai cadavers were obtained from body donation with informed consent previously signed by the donors. The cadavers were both male ( 25 bodies) and female (14 bodies) aged between 44-89 years. Infratemporal regions were bilaterally dissected ( 35 right and 38 left hemifaces). The temporalis tendon and masseter muscle were detached and resected from the mandible. The zygomatic arch and the ramus of mandible above the neck area and at an angle were cut away to expose the infratemporal region. The mandibular nerve and maxillary artery and their branches were identified before removing the lateral pterygoid muscle. The number of ATN roots was determined based on the reference point at the terminal trunk of the PMN. The communicating branch was classified from the ATN root that not specifically generated from the mandibular nerve. The neurovascular relationship of the ATN and contents in the infratemporal region were documented and photographed. The number of the ATN root, communicating branch, enclosed pattern with the MMA were calculated as the percentage.

\section{RESULTS}

The results showed that the PMN gave 4 different root variants to form the ATN (Fig. 1). The 2-root model

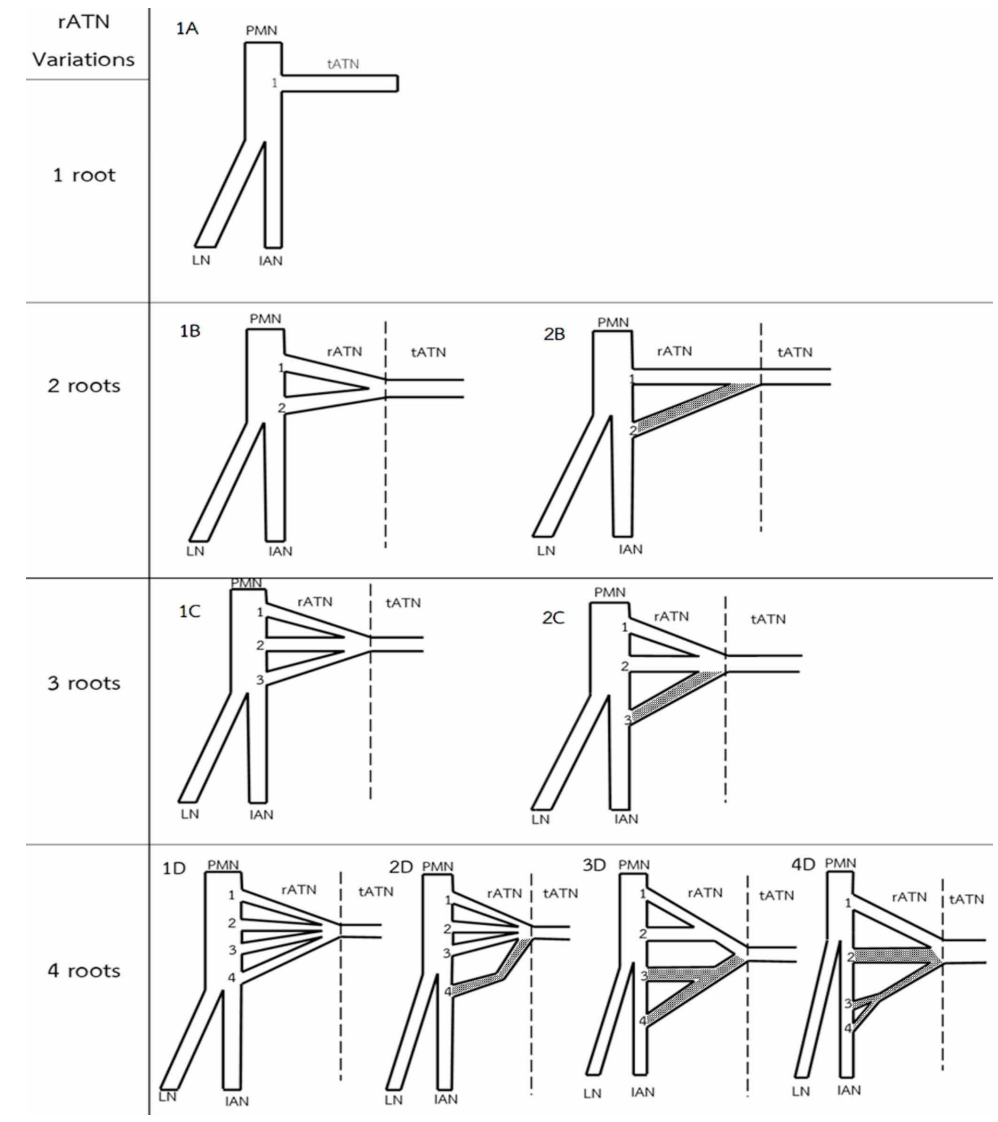

Fig. 1. Schematic variations at the root of ATN (rATN) and its auriculotemporal nerve (trunk) (tATN). Nerve structure examination demonstrating in 1-4 rATN patterns. The communicating branch from inferior alveolar nerve (IAN) presenting in grey, lingual nerve (LN), posterior division of mandibular nerve (PMN), and 1, 2, 3, 4: number of the rATN. 
was the most common pattern found from 73 Thai hemisectioned heads $(67.1 \%)$ (Fig. 2), which was higher in males $(61.2 \%)$ than females (38.8\%). In addition, this common configuration was found more on the left $(57.1 \%)$ than the right hemiface $(48.9 \%)$. The variations of 3,1 , and 4 roots were distinguished in $15.1 \%, 9.5 \%$, and $8.2 \%$ respectively (Table I).

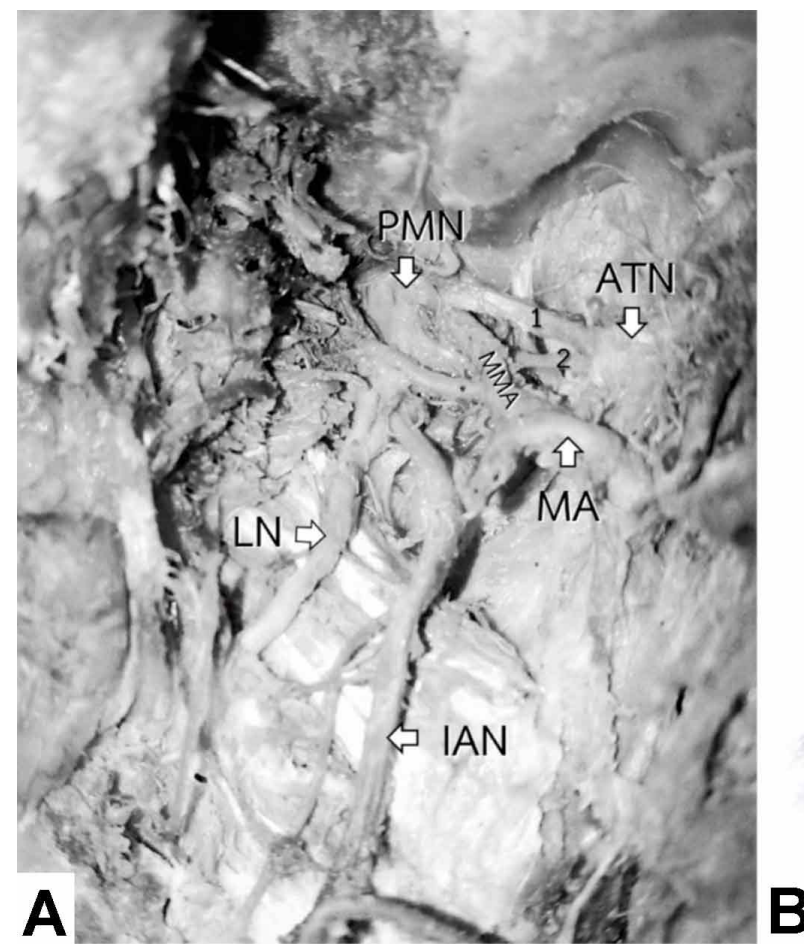

The rATN formed the connection exclusively with the IAN. From the total specimens, 10 hemi-dissected faces (13.7 $\%$ ) were found to form the communicating branch which was divided predominantly into 9 male and 1 female hemifaces. The connecting branch between ATN and IAN from 10 hemifaces was presented on the right ITR of 6 hemifaces; the other 4 hemifaces were on the left ITR (Table I).

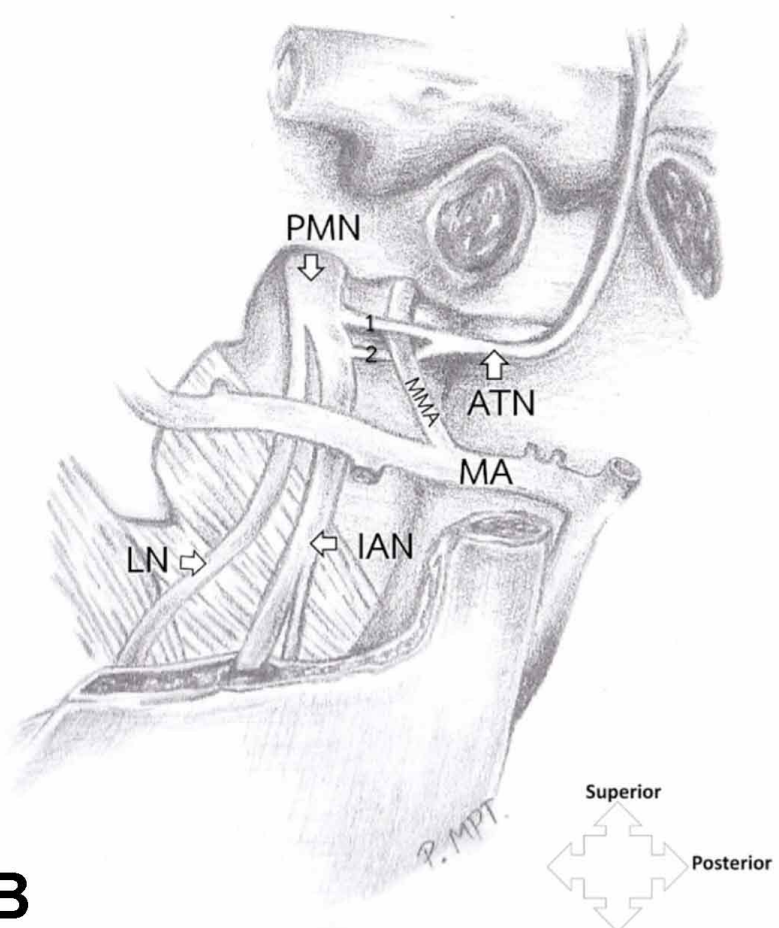

Fig. 2. A photograph (A) and an illustration (B) of left infratemporal fossa dissection and contents. The upper (1) and lower (2) roots of the auriculotemporal nerve (ATN) pass lateral and medial to the middle meningeal artery (MMA) respectively. The topographic relation of the ATN to other neurovascular structures of lingual nerve (LN), inferior alveolar nerve (IAN), and maxillary artery (MA) was demonstrated.

Table I. Nerve root variation and relation of the auriculotemporal nerve (ATN) to other structures in the infratemporal region (ITR). Showing roots of the ATN (rATN) originated from the posterior mandibular nerve, the communicating branch of the ATN to the inferior alveolar nerve (IAN), the relation of the ATN and vascular distribution within the infratemporal area; middle meningeal artery (MMA), maxillary artery (MA) and accessory meningeal artery (AMA).

\begin{tabular}{|c|c|c|c|c|c|c|c|c|c|c|c|}
\hline \multirow[t]{3}{*}{ Specimens } & \multirow[t]{3}{*}{$\mathbf{N}$} & \multicolumn{4}{|c|}{$\begin{array}{c}\text { Roots of ATN } \\
\text { N ( \%) }\end{array}$} & \multirow{2}{*}{$\begin{array}{c}\text { Communication } \\
\text { with } \\
\text { IAN } \\
\mathbf{N}(\%)\end{array}$} & \multicolumn{2}{|c|}{$\begin{array}{c}\text { Relation of } \\
\text { ATN \& MMA } \\
\text { N ( \%) }\end{array}$} & \multirow[t]{2}{*}{$\begin{array}{l}\text { AMA } \\
\text { N ( \%) }\end{array}$} & \multicolumn{2}{|c|}{ Origin of AMA } \\
\hline & & 1 & 2 & 3 & 4 & & Enclosed & No & & MA & MMA \\
\hline & & root & roots & roots & roots & & & Enclosed & & $\mathbf{N}(\%)$ & $\mathbf{N}(\%)$ \\
\hline Hemiface & 73 & $\begin{array}{c}7 \\
(9.5)\end{array}$ & $\begin{array}{c}49 \\
(67.1)\end{array}$ & $\begin{array}{c}11 \\
(15.1)\end{array}$ & $\begin{array}{c}6 \\
(8.2)\end{array}$ & $\begin{array}{c}10 \\
(13.7)\end{array}$ & $\begin{array}{c}51 \\
(69.8)\end{array}$ & $\begin{array}{c}22 \\
(30.1)\end{array}$ & $\begin{array}{c}16 \\
(21.9)\end{array}$ & $\begin{array}{c}4 \\
(25.0)\end{array}$ & $\begin{array}{c}12 \\
(75.0)\end{array}$ \\
\hline Male & 47 & $\begin{array}{c}5 \\
(10.6)\end{array}$ & $\begin{array}{c}30 \\
(63.8)\end{array}$ & $\begin{array}{c}9 \\
(19.2)\end{array}$ & $\begin{array}{c}3 \\
(6.3)\end{array}$ & $\begin{array}{c}9 \\
(90.0)\end{array}$ & $\begin{array}{c}35 \\
(74.4)\end{array}$ & $\begin{array}{c}12 \\
(25.5)\end{array}$ & $\begin{array}{c}9 \\
(56.3)\end{array}$ & $\begin{array}{c}2 \\
(22.2)\end{array}$ & $\begin{array}{c}7 \\
(77.8)\end{array}$ \\
\hline Female & 26 & $\begin{array}{c}2 \\
(7.7)\end{array}$ & $\begin{array}{c}19 \\
(73.0)\end{array}$ & $\begin{array}{c}2 \\
(7.7)\end{array}$ & $\begin{array}{c}3 \\
11.5)\end{array}$ & $\begin{array}{c}1 \\
(10.0)\end{array}$ & $\begin{array}{c}16 \\
(61.5)\end{array}$ & $\begin{array}{c}10 \\
(38.4)\end{array}$ & $\begin{array}{c}7 \\
(43.7)\end{array}$ & $\begin{array}{c}2 \\
(28.6)\end{array}$ & $\begin{array}{c}5 \\
(71.4)\end{array}$ \\
\hline Right & 35 & $\begin{array}{c}4 \\
(11.4)\end{array}$ & $\begin{array}{c}21 \\
(60.0)\end{array}$ & $\begin{array}{c}7 \\
(20.0)\end{array}$ & $\begin{array}{c}3 \\
(8.5)\end{array}$ & $\begin{array}{c}6 \\
(60.0)\end{array}$ & $\begin{array}{c}26 \\
(74.2)\end{array}$ & $\begin{array}{c}9 \\
(25.7)\end{array}$ & $\begin{array}{c}8 \\
(50.0)\end{array}$ & $\begin{array}{c}2 \\
(25.0)\end{array}$ & $\begin{array}{c}6 \\
(75.0)\end{array}$ \\
\hline Left & 38 & $\begin{array}{c}3 \\
(7.8)\end{array}$ & $\begin{array}{c}28 \\
(73.6)\end{array}$ & $\begin{array}{c}4 \\
(10.6)\end{array}$ & $\begin{array}{c}3 \\
(7.9)\end{array}$ & $\begin{array}{c}4 \\
(40.0)\end{array}$ & $\begin{array}{c}25 \\
(65.7)\end{array}$ & $\begin{array}{c}13 \\
(34.2)\end{array}$ & $\begin{array}{c}8 \\
(50.0)\end{array}$ & $\begin{array}{c}3 \\
(37.5)\end{array}$ & $\begin{array}{c}5 \\
(62.5)\end{array}$ \\
\hline
\end{tabular}


The ATN encircling the MMA was identified in 51 hemifaces $(69.8 \%)$. In male specimens, the enclosing pattern was presented in 35 infratemporal fossae, whereas 12 hemifaces had no loop of the ATN. Females showed 16 enclosed MMA pattern and 10 with no enclosed pattern. Enclosing pattern of the ATN around MMA were observed in 39 specimens $(79.6 \%$ ) from the total of 49 hemi-dissected faces in the common two-roots model. Comparing bilateral infratemporal fossa, the loop of the ATN around the MMA was demonstrated without significantly different between both sides (Table I). The accessory meningeal artery (AMA) branched from the MMA or MA was observed in 16 hemifaces accounting for $21.9 \%$ from the total of 73 specimens. There was no variation between the left and the right in this category (Table I).

\section{DISCUSSION}

The ATN is usually described as having 2 roots from the PMN and encircles the MMA in anatomical literature. However, there are more emerging information include a variety of the ATN and their relationships with neurovascular structures in the infratemporal fossa has been reported (Gülekon et al.; Komarnitki et al., 2015). The study in anatomy of the ATN in Asian ethnic groups such as Singapore (Thotakura et al., 2013), and India (Quadros et al., 2016) revealed a 1-5 root pattern in the ATN variation. The most common pattern found in the previous studies was the 2root variant, which was similar to this study with Thai population. The studies in the Caucasian specimens are more diverse within 1-5 roots patterns. The most common 1 root, 2 root, and 3 root variants were presented in the Turks, New Zealanders, and Poles respectively (Gülekon et al.; Dias et al.; Komarnitki et al., 2015). The communication of the PMN branches has been reported in many studies. The variation of communicating branches with the ATN was mostly established from the IAN (Kim et al., 2004; Thotakura et al.). Studying in the Thai cadavers, Singsorn et al. demonstrated 5 types of the PMN branch connection. The communicating nerve from the IAN and the ATN, which exclusively found in this study, accounting for $13.7 \%$ of 73 specimens which comparable to $7.14 \%$ of 55 hemifaces reported from the previous study (Singsorn et al.).

In the aspect of the ATN and MMA relation, this study was congruent with other published studies. The primarily encircle pattern of two roots around the MMA was reported $79.6 \%$ in Thai specimens comparing to $83.3-100 \%$ of Caucasian and Indian specimens. However, not enclosing the MMA by the ATN was also identified from 16.1 to 20.4 $\%$ in the two root variants (Baumel et al.; Schmidt et al.;
Komarnitki et al., 2012; Quadros et al.). In this study, the upper and lower roots of the ATN were recognized as a Vshaped form with enclosed the MMA similar to the Baumel et al. and Gülekon et al. The "buttonhole" pattern as usually described in the anatomical texts were not found (Standring, 2008). The high variation of the ATN structure and its relation to the MMA has been emphasized from upcoming publications. However, it is controversial to reconcile the ethnic variation from the limited ethnicity in the studies and the limited number of the samples. Besides, there are different criteria to determine rATN and define the communicating branch (Gülekon et al.; Komarnitki et al., 2012). Nerve roots originating from both PMN and IAN were characterized as the rATN (Komarnitki et al., 2012). In this study, the rATN was determined when it originated directly from PMN superior to a bifurcation of LN and IAN. Others from the LN or IAN were described as connecting branches. Despite the clear criteria to identify the ATN nerve roots; the study was limited by the number of specimens. This study brings additional information to assist the anatomical variation of neurovascular architecture in the ITR. The relation between ATN and MMA is important to understand in terms of sub-temporal areas approaching. Variable topography of ATN and its relationship with the muscle of mastication, blood vessels, and TMJ is likely to create nerve compression and symptomatology of headache and pain (Fernandes et al., 2003; Soni et al.). Therefore, it is essential to understand the anomalous topographic map in this limited and difficult to access area to effectively diagnose and perform local anesthesia or surgery.

\section{ACKNOWLEDGEMENTS}

The authors wish to thank the medical science students, Naresuan University for participating in the cadaver dissection. We would like to thank Mrs. Kotchakorn Siripattanaphol, MSc. student, Department of Anatomy, Faculty of Medicine Siriraj Hospital for drawing the ATN diagram. Especially acknowledge for those body donors who help to advance anatomical education and research.

CHANASONG, R.; KITI-NGOEN, K.; KHAODAENG, C.; SAKULSAK, N. \& CHOOMPOO, N. Variación anatómica del nervio auriculotemporal en cadáveres tailandeses. Int. J. Morphol., 38 (6):1657-1661, 2020.

RESUMEN: El nervio auriculotemporal (NAT) es una estructura importante que se encuentra dentro de la región infratemporal (ITR). El NAT se origina en la rama posterior de la división mandibular del nervio trigémino (V3), y transmite fibras somato sensoriales, secreto motoras y parasimpáticas del V3 y del 
nervio gustativo (CN IX). En la literatura, se reporta que el patrón más común de NAT está compuesto por 2 raíces que contienen la arteria meníngea media (AMM). Sin embargo, en diversos estudios, se ha informado que existen múltiples variaciones en la formación de patrones NAT. Con el objetivo de estudiar la variación de la formación del patrón NAT en cadáveres tailandeses, se disecaron 73 estructuras hemi faciales de 39 cadáveres tailandeses y se registraron las relaciones del NAT con el AMM. En conclusión, se observaron 4 patrones en los cadáveres tailandeses. El patrón común de 2 raíces $(67,1 \%), 3$ raíces $(15,1 \%), 1$ raíz $(9,6 \%)$ y 4 raíces $(8,2 \%)$. El conocimiento de esta variación en el NAT puede ser útil para comprender los síntomas de dolor temporo-orofacial, parestesia de la articulación temporomandibular (ATM), posibles efectos secundarios de la cirugía de ATM y la eficacia del bloqueo del nervio auriculo- temporal para la anestesia regional de la articulación temporomandibular en Tailandeses.

PALABRAS CLAVE: Nervio auriculotemporal; Nervio alveolar inferior; Arteria meníngea media; Variación; Cadáver tailandés.

\section{REFERENCES}

Baumel, J. J.; Vanderheiden, J. P. \& McElenney, J. E. The auriculotemporal nerve of man. Am. J. Anat., 130(4):431-40, 1971.

Bhardwaj, N.; Sahni, P.; Singhvi, A.; Nayak, M. \& Tiwari, V. Anomalous bilateral communication between the inferior alveolar nerve and the auriculotemporal nerve: a rare variation. Malays. J. Med. Sci., 21(5):714, 2014.

Boonruangsri, P.; Chaisiwamongkol, K.; Iamsaard, S. \& Arun, S. Entrapment of posterior divisions of the mandibular nerve by the lateral pterygoid muscle. Srinagarind Med. J., 34(4), 2019. Available from: https://li01.tci-thaijo.org/index.php/SRIMEDJ/article/view/200743

Dias, G. J.; Koh, J. M. C.; \& Cornwall, J. The origin of the auriculotemporal nerve and its relationship to the middle meningeal artery. Anat. Sci. Int., 90(4):216-21, 2015.

Drake, R. L.; Vogl, W. \& Mitchell, A. W. M. Gray's Anatomy for Students. Philadelphia, Elsevier/Churchill Livingstone, 2005. pp.872-98.

Fernandes, P. R. B.; de Vasconsellos, H. A.; Okeson, J. P.; Bastos, R. L., \& Maia, M. L. T. The anatomical relationship between the position of the auriculotemporal nerve and mandibular condyle. Cranio, 21(3):16571, 2003.

Gülekon, N.; Anil, A.; Poyraz, A.; Peker, T.; Turgut, H. B. \& Karaköse, M. Variations in the anatomy of the auriculotemporal nerve. Clin. Anat., 18(1):15-22, 2005.

Kim, S. Y.; Hu, K. S.; Chung, I. H.; Lee, E. W. \& Kim, H. J. Topographic anatomy of the lingual nerve and variations in communication pattern of the mandibular nerve branches. Surg. Radiol. Anat., 26(2):128-35, 2004.

Komarnitki, I.; Andrzejczak-Sobocinska, A.; Tomczyk, J.; Deszczynska, K. \& Ciszek, B. Clinical anatomy of the auriculotemporal nerve in the area of the infratemporal fossa. Folia Morphol. (Warsz.), 71(3):18793, 2012.

Komarnitki, I.; Tomczyk, J.; Ciszek, B. \& Zalewska, M. Proposed classification of auriculotemporal nerve, based on the root system. PLoS One, 10(4):e0123120, 2015.

Quadros, L. S.; Jaison, J.; Bhat, N.; Prasanna, L. C.; Bhat, K. M. R. \& Kalthur, S. G. Auriculotemporal nerve - A study on its root. Online J. Health Allied Sci., 15(1):1-3, 2016.

Schmidt, B. L.; Pogrel, M. A.; Necoechea, M. \& Kearns, G. The distribution of the auriculotemporal nerve around the temporomandibular joint. Oral Surg. Oral Med. Oral Pathol. Oral Radiol. Endod., 86(2):165-8, 1998.

Singsorn, J.; Boonruangsri, P.; Chaisiwamongkol, K.; Kanla, P.; Khonkankong, W.; Toomsan, Y. \& Iamsaard, S. A morphological study of posterior divisional branches of the mandibular nerve in embalmed Thai cadavers. Srinagarind Med. J. 30(4):358-63, 2015. Available from: https://li01.tci-thaijo.org/index.php/SRIMEDJ/article/view/41390

Soni, S.; Rath, G.; Suri, R. \& Vollala, V. R. Unusual organization of auriculotemporal nerve and its clinical implications. J. Oral Maxillofac. Surg., 67(2):448-50, 2009.

Standring, S. Gray's Anatomy. The Anatomical Basis of Clinical Practice. $40^{\text {th }}$ ed. Edinburgh, Churchill Livingstone, 2008.

Thotakura, B.; Rajendran, S. S.; Gnanasundaram, V. \& Subramaniam, A. Variations in the posterior division branches of the mandibular nerve in human cadavers. Singapore Med. J., 54(3):149-51, 2013.

\author{
Corresponding author: \\ Narawadee Choompoo \\ Department of Anatomy \\ Faculty of Medical Science \\ Naresuan University \\ Phitsanulok \\ THAILAND
}

Email: narawadeec@nu.ac.th

Received: $16-06-2020$

Accepted: 12-07-2020 